Hertz, S., Bernier, A., Regueiro, S., \& Cimon-Paquet, C. (2019). Parent-child relationships and child executive functioning at school entry: The importance of fathers. Early Child Development and Care, 189, 718-732. 


\begin{abstract}
This study aimed to examine the unique and interactive contributions of the quality of mothers' and fathers' relationships with their toddlers to the prediction of children's subsequent executive functioning (EF). The sample included 46 low-risk middle-class families. The quality of motherchild and father-child interactions was assessed independently during separate interactive sequences at 18 months. Child EF problems were reported by teachers in kindergarten. The results indicated that only father-child interactions made a unique contribution to the prediction of children's EF, and no interaction effect was observed. Kindergarteners who benefited from higher-quality interactions with their fathers in toddlerhood were considered by their teachers to present fewer EF problems in everyday school situations. These results appeared to be somewhat more pronounced in father-son than father-daughter dyads. Overall, the results suggest that fathering and father-child relationships may deserve more empirical attention than they have received thus far in the EF literature.
\end{abstract}

Key words: kindergarten, school entry, cognitive development, executive functioning, motherchild interactions, father-child interactions. 


\section{Parent-Child Relationships and Child Executive Functioning at School Entry: The Importance of Fathers}

Parents, teachers, and scientists agree that school entry may be one of the most significant developmental milestones of early childhood. Initial entry into the formal school system (generally in kindergarten) has been described as a time of both opportunity and risk, given the numerous challenges that children must handle simultaneously (Ladd \& Price, 1987; Pianta, Cox, \& Snow, 2007): notably, adjusting to a new peer group, a new teacher and a larger child-to-adult ratio. In addition, when children first come to school, they are expected to sit still and to direct their attention to tasks, some interesting, some tedious. They also need to listen and follow rules that differ from those at home.

To thrive in such an environment, children need to harness their attention, suppress impulses, and control their actions. The skills that are crucial to do so are often referred to as executive functioning (EF), which consists of a set of higher-order cognitive abilities, such as impulse control, set-shifting, planning, and working memory (Zelazo, Carlson, \& Kesek, 2008). These functions are thought to be foundational for children's successful functioning in school contexts, in that they underlie many aspects of cognition and behavior that are crucial in school (Blair, 2002). EF is influential not only in acquisition of knowledge, but also contributes to establishing a behavioral predisposition for learning and for interacting appropriately with peers and teachers (Bierman, Nix, Greenberg, Blair, \& Domitrovich, 2008; Diamond, 2002). In line with these claims, empirical research shows that better EF relates to higher social (Hughes \& Ensor, 2008) and academic competence in young children (Clark, Pritchard, \& Woodward, 2010), including across the transition to school (Hughes \& Ensor, 2011). Overall, studies suggest that children who have better EF when they enter school possess richer cognitive and behavioral 
regulation skills, which allow them to engage effectively in active learning and to succeed in school (Blair \& Raver, 2014).

Teachers would surely agree, however, that young children vary greatly in their executive capacities when they enter school. Identification of the origins of these individual differences in children's EF has been the focus of much research attention. Research has traditionally focused on biological factors, notably maturation of the prefrontal cortex (see Diamond, 2002; Kraybill \& Bell, 2013). However, there is increasing evidence that environmental factors also can explain individual differences in children's EF capacities (Fay-Stammbach, Hawes, \& Meredith, 2014; Shonkoff et al., 2011). Given that the family is the main socialization setting during the preschool period, parent-child relationships appear to be central environmental factors that can foster children's executive development and thus prepare children for school. The current study focuses on the quality of early parent-child relationships as one possible candidate to explain individual differences in children's EF as manifested in kindergarten.

\section{Parent-Child Relationships and Child EF}

Several studies have explored the associations between the quality of the relationship with one parent and children's EF and suggest that higher-quality parent-child interactions are associated with better child performance on executive tasks (e.g., Bernier, Carlson, Deschênes, \& Matte-Gagné, 2012; Hammond, Müller, Carpendale, Bibok, \& Liebermann-Finestone, 2012). In those studies, the quality of parent-child interactions has mostly been defined as the quality of parental behavior, operationalized as sensitivity/responsiveness, scaffolding/autonomy support, stimulation, or control (see Fay-Stammbach et al., 2014, for a review). Other studies have focused on the affective bond characterizing the mother-child relationship, as measured through children's attachment behavior (e.g., Bernier, Beauchamp, Carlson, \& Lalonde, 2015). 
Although studies have mainly focused on mothers (e.g., Bernier, Carlson, \& Whipple, 2010; Cuevas et al., 2014; Kraybill \& Bell, 2013), there is no theoretical reason to exclude paternal influences, especially considering that fathers play an important role in children's social and cognitive development (Leidy, Schofield, \& Parke, 2013; Tamis-LeMonda, Baumwell, \& Cabrera, 2013). Notably, paternal influence has been shown to promote child language and literacy (Tamis-LeMonda, Shannon, Cabrera, \& Lamb, 2004; see Saracho, 2007 and Varghese \& Wachen, 2016, for reviews). In addition, a recent meta-analysis by Kim and Hill (2015) reveals that paternal involvement is associated with school-aged children's academic achievement, and this association is equally strong for fathers and mothers.

In fact, the few EF studies that have focused on fathers did find that the quality of fatherchild relationships was positively related to children's EF (e.g., Kochanska, Askan, Prisco, \& Adams, 2008; Meuwissen \& Carlson, 2015). Overall, existing research clearly suggests that young children exposed to higher-quality interactions with their mothers, and to an extent their fathers, demonstrate better concurrent and subsequent EF, which presumably allows them to engage effectively in self-regulated learning when they reach school.

However, as highlighted in recent papers (Fay-Stammbach et al., 2014; Meuwissen \& Carlson, 2015), very few EF studies have truly considered unique and combined contributions of both parents. The majority of studies focused on samples of either mothers or fathers, not both. However, following theoretical propositions concerning the presumed distinct roles of mothers and fathers (described below), one may hypothesize that each parent could contribute differentially to the development of his or her child's EF, and thus that simultaneous consideration of maternal and paternal influences is necessary to fully understand parental contributions to children's executive development. 


\section{Mother-Child vs. Father-Child Relationships: Theoretical Perspectives}

It is a long-standing hypothesis that mothers and fathers could play different caregiving roles, thereby each contributing in unique ways to their children's development (Newland et al., 2013; Owen et al., 2013). For instance, some authors suggest that fathers are more likely to support children's exploration through play, providing them with challenge and encouraging openness to the outside world, whereas mothers would be more likely to take on the role of emotional support in distressing situations, thus providing emotional security (Grossmann et al., 2002; Paquette, 2004). More broadly, any mother-father complementarity is presumed to contribute to optimal child functioning (Cabrera, Fitzgerald, Bradley, \& Roggman, 2014; Martin, Ryan, \& Brooks-Gunn, 2007). The hypothesis is that in two-parent families, parents can have different but complementary behavioral tendencies that can compensate for each other's weaknesses, and/or reinforce each other's influence on the child. Thus, by studying parents in combination, it may be possible to identify interactions that are not apparent in studies of main effects. For example, the beneficial influence of a high-quality relationship with one parent may be magnified in the context of a high-quality relationship with the other parent; alternatively, a better relationship with one parent could act as a buffer against a lower-quality relationship with the other parent. In sum, both additive and interactive models appear plausible when it comes to parental influences on child EF, making simultaneous consideration of mothers and fathers an important endeavor in this field.

\section{Mother-Child vs. Father-Child Relationships: Empirical Findings}

Recently, some studies have considered both mothers and fathers in their analyses to assess the unique contribution of each parent. In general, these studies support the hypothesis that each parent makes a unique contribution to the prediction of child cognitive functioning (e.g., 
Belsky et al., 2008; Tamis-LeMonda et al., 2004). A handful of studies have specifically considered unique maternal and paternal contributions to child EF. Towe-Goodman et al. (2014) found that both fathers' and mothers' sensitive and supportive parenting during infancy and toddlerhood was significantly predictive of children's EF at 3 years of age, with unique contributions for each parent. Likewise, Karreman, van Tuijl, van Aken, and Dekovic (2008) found that both maternal and paternal parenting quality made a unique contribution to the prediction of children's effortful control at 3 years. Finally, Roskam, Stievenart, Meunier, and Noël (2014) found that both maternal and paternal self-reported parenting were related to child EF from 2 to 8 years of age. However, when both parents were considered in a single model, only maternal parenting remained a significant predictor. Overall, these studies support the importance of considering both parents in the search for the origins of individual differences in children's EF. It should be noted, however, that these studies examined the unique (additive) contributions of each parent, while there may be value in considering also their combined (interactive) effects.

Few studies appear to have formally investigated the interactive effects of the quality of mother-child and father-child relationships, and those that did have often examined parent-child attachment in relation to child socio-emotional functioning. Two of these studies found significant interactions such that children who had secure attachments to both their parents showed superior social skills (Suess, Grossmann \& Sroufe, 1992; Verschueren \& Marcoen, 1999). More recently, Kochanska and Kim (2013) also found an interactive effect, suggesting that children with insecure attachments to both their parents had more behavior problems than those who had at least one secure attachment.

Closer to our purposes, other studies have investigated interactive effects of mother-child and father-child relationships in the cognitive and academic domains. Flouri and Buchanan 
(2004) examined whether the link between one parent's involvement and youths' achieved level of education at age 20 years was moderated by the other parent's involvement; no significant interactive effect was found. In contrast, Diener, Isabella, Behunin, and Wong (2008) found a significant interaction, such that children who had secure attachments to both their parents held significantly higher perceptions of their own academic skills than their peers who were securely attached to only one of their parents. Finally, Martin et al. (2007) examined the relation between maternal and paternal parenting and 5-year-old children's language and mathematical skills in low-income families. The authors found additive but no interactive effects. Overall then, when considering academic and cognitive functioning, the evidence regarding putative interactive effects of both parents is quite mixed.

To our knowledge, no study to date has examined the unique and interactive contributions of the quality of mother-child and father-child early relationships to the prediction of child EF. Investigating this question in relation to the everyday manifestations of child EF at school entry was the purpose of this study.

\section{The Current Study}

A primary objective of this study was to test the hypothesis that the quality of the relationship with each parent makes a unique contribution to the prediction of child $\mathrm{EF}$ as manifested subsequently in the classroom, such that higher-quality relationships are associated with fewer EF problems at school. As mentioned earlier, the quality of parent-child interactions has generally been operationalized in the EF literature based on behavioral and emotional indicators observed in the parent or the child, independently. Other measures, targeting the dyad rather than the individuals separately, are likely to provide an especially rich assessment of the parent-child relationship. Thus, in the current study, the quality of parent-child interactions was 
assessed via the construct of Mutually Responsive Orientation, defined as the mutual, bidirectional, and reciprocal qualities of the dyadic interplay between parent and child (Kochanska et al., 2008). A second objective was to investigate interactive effects between the quality of mother-child and father-child relationships. Given the mixed results found in prior research on cognitive outcomes, presented above, no a priori hypothesis was formulated, and this question was examined in an exploratory manner.

\section{Method}

\section{Participants}

Eighty-two intact families living in a large Canadian metropolitan area participated in this study. These families were recruited from random birth lists generated by the Ministry of Health and Social Services. Criteria for participation were full-term pregnancy and the absence of known developmental delays. There were 49 girls (59.8\%) and most children (74.4\%) had no sibling. Socio-demographic information was gathered when infants were 8 months old. At that time, mothers were between 20 and 45 years old $(M=31.37)$ and had 15.35 years of education on average (varying from 11 to 18 years). Fathers were between 24 and 55 years old $(M=34.18$ ) and had 15.41 years of education on average (varying from 11 to 21 years). Most mothers (67.1\%) and fathers (64.6\%) held a college degree (63.3\% of parents in the province of Quebec, where this study was conducted, hold a college degree; www.stat.gouv.qc.ca). Family income was based on categorical scores distributed as follows: $1<20 \mathrm{~K} \$ ; 2=20-39 \mathrm{~K} \$ ; 3=40-59 \mathrm{~K} \$ 44=$ $60-79 \mathrm{~K} \$ ; 5=80-99 \mathrm{~K} \$ ; 6=99 \mathrm{~K} \$$ and over. Mean family income for the sample was 4.63 (SD = 1.58 ), near the mean family income in Canada which was $\$ 74,600$ for the years of data collection. The majority of mothers $(83.7 \%)$ and fathers $(77.6 \%)$ were Caucasian and Frenchspeaking (78.7\% of mothers and $75.9 \%$ of fathers), comparable to federal statistics that indicate 
that the local population is predominantly Caucasian (83.2\%; Statistics Canada, 2006) and French-speaking (80\%; Statistics Canada, 2011).

\section{Procedure}

Data were collected during two visits. The first visit (T1) took place in our laboratory, when children were 18 months of age $(M=18.19 ; S D=0.92)$. First, mothers $(N=82)$ were invited to share a snack with their child (see Moss, Cyr, \& Dubois-Comtois, 2004 for a similar

procedure). This lasted approximately 10 minutes. Second, research tasks were administered to the child, which are not used in this report (approximately 20 minutes). Next, fathers $(N=82)$ were invited to play with their child for 10 minutes with a set of age-appropriate toys provided by the research team. These different contexts were chosen because they were deemed well suited to each dyad. Indeed, mothers, especially with young children, spend more time in caregiving contexts including feeding, whereas fathers are proportionally more involved in play contexts than mothers (John, Halliburton, \& Humphrey, 2013; Lamb \& Lewis, 2010; Schoppe-Sullivan, Kotila, Jia, Lang, \& Bower, 2013). Each parent was alone with his or her child during the parentchild interaction, while the other parent was in a separate room with the research assistants. These interactive sequences were videotaped, and later rated independently by trained assistants with the Mutually Responsive Orientation scale (MRO, described below), to ensure methodological independence of mother-child and father-child data.

When children were in the Spring of their kindergarten year (February through April T2; $M=72.04$ months of age; $S D=2.70 ; N=68$ ), their teachers were asked to complete the Behavior Rating Inventory of Executive Function - Preschool Version (BRIEF-P) and to return it to our laboratory with a provided pre-paid envelope. Forty-six $(67.65 \%)$ teachers returned the questionnaire. These 46 families did not differ from the 22 families for whom no teacher 
assessment was available on socio-demographics, mother-child MRO scores, or father-child MRO scores (all p's $>$.14). However, the 14 families who had left the study between T1 and T2 differed from those who stayed on some variables. Those who left had marginally lower fatherchild MRO scores $(t(80)=1.86, p=.07)$, lower family socioeconomic status (SES, a standardized averaged score of maternal and paternal education and family income; $t(80)=2.58$, $p=.01$ ), and were more likely to have one child only (inequality of variances; $t(31,34)=2.46, p$ $=.02)$.

\section{Measures}

Mutually Responsive Orientation scale (MRO; Aksan, Kochanska, \& Ortmann, 2006). The MRO is an observational measure of the quality of parent-child interactions, intended to be used in different contexts, for instance having a snack, bathing and dressing the child, or free play. In this study, we used the MRO to rate the mother-child snack and the father-child free play. In line with Aksan and colleagues (2006), we first rated Harmonious Communication, Mutual Cooperation, and Emotional Ambiance as three distinct subscales (the original Coordinated Routine subscale was dropped because it refers to routine activities that become scripted over time, and therefore did not apply to the free-play or snack situations). The Harmonious Communication subscale measures the extent to which both verbal and non-verbal aspects of communication flow smoothly. The Mutual Cooperation subscale measures the extent to which the dyad effectively resolves potential sources of conflict and the extent to which parent and child are open to each other's influence. The Emotional Ambiance subscale measures the extent to which the dyad enjoys an emotionally positive atmosphere indicating pleasure in each other's company. As recommended by Aksan et al. (2006), these three scores were averaged into a global score indexing the quality of mother-child or father-child interactions. Scores vary from 
1 to 5 , with 1 indicating a disconnected, unresponsive, hostile, and/or affectively negative interaction, and 5 reflecting a mutually responsive, harmonious, cooperative, and/or affectively positive interaction between parent and child.

The MRO has excellent psychometric properties, including excellent internal consistency for the global score (Cronbach's $\alpha=.90$; Aksan et al., 2006) and good inter-rater reliability (kappa $=.72$; Aksan et al., 2006). Reliability was excellent in the current sample as well, with high internal consistency (Cronbach's $\alpha=.96$ for mothers and .97 for fathers) and inter-rater reliability (intra-class correlation $=.95$ for mothers and .86 for fathers; $25 \%$ of interactions were independently double-coded). The MRO also shows excellent predictive validity (e.g., children's conscience development; Kochanska \& Murray, 2000, and self-regulation; Kochanska et al., 2008). It was used in the present study to assess the quality of mother-child and father-child interactions because in addition to its advantageous dyadic nature, it is one of few coding systems that was not developed primarily for mothers and subsequently adapted for fathers, a frequent assessment issue when studying father-child relationships.

The Behavior Rating Inventory of Executive Function - Preschool Version (BRIEF-P; Gioia, Espy, \& Isquith, 2003) is a standardized questionnaire including 63 items that assess child EF problems as observed through everyday behaviors at home (with the Parent Form) or at school (with the Teacher Form). Given that this study aimed to understand children's EF as manifested in the context of the kindergarten classroom, we used the Teacher Form. Teachers are asked to rate the child's behavior on a 1 to 3 Likert scale (never, sometimes, often). Higher ratings are indicative of greater perceived impairment. From the 63 items, five executive subdomains, three indices, and an overall Global Executive Composite (GEC) can be derived. The first two subdomains, Inhibit and Emotional Control, are combined to form the 
Inhibitory/self-control index (26 items). The Shift and Emotional Control subdomains compose the Flexibility index (20 items). The other two subdomains, Working Memory and Plan/Organize, form the Emergent metacognition index (27 items). The 63 items can also be summed to create the GEC. In the current study, we used the three indices (hereafter Inhibition, Flexibility, and Metacognition) and the GEC as dependent variables. To avoid redundant analyses, the five subdomains were not used, given their linear relations to the more encompassing indices and composite.

The Teacher Form of the BRIEF-P has well-demonstrated psychometric properties (Gioia et al., 2003), including excellent internal consistency (Cronbach's $\alpha$ between .80 and .97), satisfactory test-retest reliability $(.65<r>.94)$, and documented convergent and divergent validity. To assess children's executive manifestations in the kindergarten context, the Teacher Form of the BRIEF-P is an instrument of choice, because it measures child EF as manifested in the everyday real-world context of the school setting. During visits to families' homes or lab visits, it is almost impossible for the assistants to assess all executive capacities that children may use at school. In contrast, teachers can observe a variety of situations in which children might exhibit their EF skills - or deficits (sitting still for long periods, responding to peer provocation, organizing a systematic strategy to complete a task, etc.). Thus, teacher reports may capture ecologically valid and important aspects of children's EF that are not assessed with research tasks but that are manifested and important at school (Cuevas, Hubble, \& Bell, 2012). In fact, scores on the BRIEF-P in kindergarten have been found predictive of children's subsequent mathematic achievement (Clark et al., 2010).

\section{Results}

\section{Preliminary Analyses}


Table 1 presents the descriptive statistics for the quality of mother-child and father-child interactions, as well as for child Inhibition, Flexibility, Metacognition, and the GEC. All variables showed adequate variability (although mean levels of executive problems were low), and no outliers were detected. Socio-demographic variables (child age and sex, presence of siblings, and family SES) were then analyzed as potential covariates. Due to space considerations, only those that showed marginal or significant relations to key study variables are displayed in Table 2. Child sex and presence of older (but not younger) siblings in the family were marginally related to the quality of mother-child interactions. Child age at T1 was significantly related to mother-child interactions and marginally related to father-child interactions (whereas child age at T2 did not relate to EF). Finally, family SES was significantly related to the quality of father-child interactions. Therefore, in order to run conservative and uniform analyses, child sex, number of older siblings, child age at T1, and family SES were covaried in the subsequent main analyses.

Table 2 also displays the zero-order correlations among the main study variables. The quality of father-child interactions was significantly associated with the GEC and marginally related to the metacognition index, whereas no relation was found between EF and the quality of mother-child interactions.

\section{Main Analyses}

Multiple hierarchical regressions were carried out to assess the unique and interactive effects of the quality of mother-child and father-child relationships on children's EF over and above the covariates. We ran a distinct regression for each index (Inhibitory, Flexibility, Metacognition) and for the GEC. We inserted variables in the following order: Block 1, child sex, presence of older siblings, child age (T1), and family SES; Block 2, quality of mother-child 
interactions and father-child interactions (in line with our first objective); Block 3, the multiplicative interaction term of mother-child interactions by father-child interactions (in line with our second objective). Regression diagnostics revealed that there was no multicollinearity among predictors, with all VIF's $<1.4$ (recommendation: VIF's $<5.0$ ). Results are presented in Table 3.

With respect to the indices, analyses revealed that the quality of father-child interactions made a unique, but marginal, contribution to the prediction of Inhibition $(\beta=-.36, p=.07)$. No significant results were found for Flexibility and Metacognition (although relations were in the same direction). However, when considering the GEC, the analyses revealed a unique contribution of the quality of father-child interactions $(\beta=-.38, p=.05)$, above and beyond the covariates, quality of mother-child interactions, and the interactive effect. Children who had higher-quality interactions with their fathers at 18 months were considered by their teachers to present fewer executive deficits overall in kindergarten. The quality of mother-child interactions and its interactive effect with the quality of father-child interactions were unrelated to child EF. As post-hoc analyses, models were run for fathers and mothers separately. In line with the pattern of zero-order correlations presented above, the findings remained the same as when the two parents were considered simultaneously: no contributions of mother-child interactions approached significance, and the coefficients pertaining to father-child interactions were unchanged in terms of levels of significance.

The fact that the significant findings were specific to fathers raised the possibility that child sex may be involved, such that relations to EF would be stronger among boys or girls. Indeed, several studies have shown that the influence of parental behavior on child development can differ depending on child sex (Barnett \& Scaramella, 2015; Ruiz-Ortiz, Braza, Carreras, \& 
Muñoz, 2017; Tung, Li, \& Lee, 2012). There is also evidence that fathers tend to be more available and involved with their sons than with their daughters (Harris, Furstenberg, \& Marmer, 1998; Manlove \& Vernon-Feagans, 2002; Nettle, 2008) and in fact, the impact of child sex on parenting is proposed to be especially marked among fathers (Paquette, 2004; Schoppe-Sullivan et al., 2006). For instance, Cabrera, Tamis-LeMonda, Bradley, Shannon and Hancock (2012) observed that fathers but not mothers who reported high couple conflict were less supportive of girls than of boys, and that fathers used harsh discipline more often with their sons than daughters in chaotic households. Accordingly, although the sample size did not allow us to include child sex as an additional moderator in the above equations, we performed separate correlational analyses on an exploratory basis. These analyses suggested that the link between the quality of father-child interactions and child GEC $(r=-.29, p=.05$, presented in Table 2$)$ varied somewhat according to child sex. The correlation between child global EF and quality of father-child interactions was almost three times larger in father-son dyads $(r=-.47, p=.06)$ than fatherdaughter dyads $(r=-.17, p=.37)$. However, Fischer's $Z$ test for independent correlations (Cohen \& Cohen, 1983) revealed that these two correlations were not significantly different from one another $(Z=-0.99, p=.32)$. There was no apparent effect of child sex on the relations between child EF and the quality of mother-child interactions.

\section{Discussion}

Given the numerous changes that characterize school entry, children's EF is likely to be frequently solicited. However, children are not equal in the face of this challenge. The current study suggests that part of these individual differences can be traced back years earlier in development. We investigated the capacity of parent-child relationships in early toddlerhood to predict teachers' perceptions of children's executive deficits as manifested in their everyday 
functioning in kindergarten. We hypothesized that the quality of the relationship with each parent would uniquely contribute to the prediction of child EF. The results suggested, instead, that only the quality of father-child interactions made a unique contribution to the prediction of children's overall EF, above and beyond several key covariates. With respect to the specific associations observed with the three indices, we do not think that the small differences between the magnitude of those coefficients (and the fact that one reached trend-level significance) should be seen as particularly meaningful, suggesting that fathering relates to inhibition mostly. Instead, the most robust conclusion that is suggested by the overall pattern of results is that the quality of fatherchild interactions was most clearly related to the variance that is shared between the three indices, and therefore, to EF as a whole.

Theory and previous empirical research suggest that mother-child and father-child relationships may differentially influence various aspects of child development (e.g., Boldt, Kochanska, Yoon, \& Nordling, 2014; Bretherton, 2010). Some authors (Grossmann et al., 2002; Steele \& Steele, 2005) have argued that whereas mothers provide comfort and security when children are in distress, fathers rather provide encouragement of exploration and age-appropriate challenges while playing with their young children, which would be especially salient for dealing with the outside world (e.g., at school and with peers). Fathers are believed to challenge their children, gently destabilizing them and introducing them to new situations (Paquette, 2004; StGeorge, Fletcher, Freeman, Paquette, \& Dumont, 2015). This emphasis on tackling novelty or challenges is likely to help children develop some of the skills needed to adjust to new demands, a core characteristic of EF. Thus, when children interact with their fathers, they can be hypothesized to use, practice, and thus refine their executive skills more often than when interacting with their presumably less challenge-oriented mothers. Grossmann and colleagues 
(2002) suggested that the higher levels of arousal and challenge characterizing play-based fatherchild interactions may be an important context in which children learn the regulation of affect, attention, and behavior, which constitute skills that are central to EF. Overall, the presumed unique nature of father-child interactions may offer important opportunities for children to practice their developing EF skills. In fact, other studies have found that fathering but not mothering contributed uniquely to other aspects of child functioning, such as positive affect (Diener, Mangelsdorf, McHale, \& Frosch, 2002), child adaptive functioning with peers and at school (Boldt et al., 2014), or adolescents' internalizing and externalizing behavior problems (Day \& Padilla-Walker, 2009). This said, the current study was not set up to investigate directly the proposed complementary roles of fathers and mothers. We assessed the quality of father-child and mother-child interactions along the same dimensions of communication, cooperation, and emotional ambiance, rather than examining different interactive behaviors proposed to be more salient in paternal or maternal parenting. A true test of the complementary hypothesis would require a finer-grained assessment of paternal and maternal behavior.

However, the assumption that each parent may provide qualitatively different experiences for children has been questioned; some scholars argue that the available evidence suggests that fathers and mothers are more similar than different in terms of their roles and behaviors (Fagan, Day, Lamb, \& Cabrera, 2014; McDowell \& Parke, 2009). It is also important to note that, as reviewed in the introduction, there is a great deal of evidence pointing to maternal influences on child EF (see Fay-Stammbach et al., 2014), including from studies simultaneously considering paternal influences (albeit mostly with younger children; Karreman et al., 2008; Towe-Goodman et al., 2014). Accordingly, the current findings should not be interpreted as suggesting a lack of maternal influences on child EF as manifested in the classroom; rather, they highlight that studies 
including both parents may reveal paternal influences greater than expected, perhaps especially at certain developmental periods. In fact, given that this is, to the best of our knowledge, the first study to consider both parents' influences in relation to child EF as manifested during the transition to school, and that indeed the results are in keeping with long-standing theorization about paternal functions pertaining to exploration and novelty (such as school entry), we would tentatively suggest that there may be a special role of fathers in relation to children's EF manifestations in a new context such as kindergarten. This is speculative, however, and in need of replication.

Another potential explanation for the results is the context of interactions. Mother-child interactions were assessed in a snack context and father-child interactions in a play context. Although the quality of interactions did not appear to be affected by the context (mean scores for MRO-mother and MRO-father were very similar), the nature of what was assessed probably did vary across contexts. In a play context, there are more opportunities for parents to interact with their children in a challenging manner. As mentioned earlier, such an interaction mode, if taking place in a warm, supportive atmosphere, may help children practice their EF skills. In contrast, in a snack context, parents are probably less likely to display challenging behaviors. Accordingly, it may be that by assessing fathers' capacity to maintain harmonious communication, mutual cooperation, and a positive emotional ambiance in a free-play context conducive to playful challenges, we tapped into parenting skills that are directly relevant to children's executive development. On the other hand, assessment of the same skills in a snack context (used here with mothers) may be more important in the prediction of socio-emotional aspects of child functioning. For instance, studies have found that the quality of mother-child interactions in a snack context predicts child attachment behaviors and representations (Dubois-Comtois, Cyr, \& 
Moss, 2011) as well as child behavior problems (Dubois-Comtois, Moss, Cyr, \& Pascuzzo, 2013). Thus, the observational context may be responsible for the lack of relations found here between quality of mother-child interactions and later child EF. Studies assessing both dyads in both types of contexts are needed to tease apart these different possibilities.

A third hypothesis that may explain why significant links were found only with fatherchild interactions pertains to the sequence. For all dyads, the mother-child snack took place prior to the father-child free play. One might argue that after eating their snack, children had an energy boost fostering active, dynamic father-child exchanges. The energized children may have encouraged their fathers to display more challenging behaviors, the quality of which, as mentioned above, may be especially salient in the prediction of child EF. Overall, it should be emphasized, here again, that the results of this study do not challenge the well-documented role of mothers in children's EF development, and that several conceptual (fathers' unique styles, school entry) and methodological factors (context, sequence) may account for the results observed here. The results do highlight, however, that putative paternal contributions to young children's subsequent executive manifestations in the classroom deserve attention.

A post-hoc but interesting finding was that the correlation between child EF and the quality of father-child interactions was almost three times larger in father-son compared to fatherdaughter dyads. Although unexpected, this finding is sensible, given the potentially greater involvement of fathers in playing with their toddler boys than girls. A large body of literature has demonstrated that child gender influences parenting in a variety of ways (Leaper, 2002), and it is often proposed that this may be especially so among fathers (e.g., Schoppe-Sullivan et al., 2006). Studies have found that fathers are typically more involved with their sons than daughters as early as infancy (e.g., NICHD Early Child Care Network, 2000). Furthermore, the relatively 
greater paternal reliance on play as an interaction mode would be more marked with boys, and especially observable with rough-and-tumble play (Lindsey \& Mize, 2001), which has been suggested as likely to promote children's self-regulatory capacities (Paquette, 2004; StGeorge et al., 2015). Overall, one may speculate that because many fathers are more involved with their toddler boys and play more physically with them, boys may be exposed to more opportunities than girls to use and practice their EF skills when playing with their fathers. Recall, however, that the differences between father-son and father-daughter dyads in the MRO-EF links, albeit substantial in size, were not statistically significant in this small sample.

The second purpose of this study was to investigate the interactive effects between the quality of mother-child and father-child interactions. Interactive effects were non-significant. Several explanations can be proposed for this null finding. Most obviously, the sample size was modest, which negatively impacted statistical power, and interactive effects require more power than main effects to be detected. It could also be that, as mentioned above, the snack context in which mother-child interactions were assessed was non-optimal with regards to the aim of identifying parental predictors of child EF. There is no doubt that this issue, if it was indeed problematic, undermined the current study's ability to find not only main effects but also interactive effects involving mother-child interactions. Lastly, the null hypothesis could be true, such that there is no interactive effect between the quality of mother-child and father-child interactions during toddlerhood in the prediction of child EF in kindergarten. In fact, as mentioned earlier, the results of studies that have investigated the combined effects of motherchild and father-child relationships on child cognitive functioning are equivocal, providing little evidence for interaction effects.

\section{Limitations and Future Research}


This study presents methodological limitations that call for careful interpretation of the results. Given the correlational design, we cannot conclude that the found associations are indicative of causal relations. As mentioned above, the very modest sample size weakened statistical power, perhaps contributing to our failure to find main or interactive effects with mother-child interactions. It is important to note, however, that no result pertaining to motherchild interactions approached significance; all regression coefficients (for main and interactive effects) were much smaller than those pertaining to father-child interactions. Accordingly, it is unlikely that statistical power played a major role in those non-significant results. The other main issue with small samples is that they are more vulnerable to extreme scores that could bias analytic results; however, as indicated in the preliminary analyses, score distributions were examined formally and no outliers were detected. Overall, the small sample probably had little bearing on this study's findings; nevertheless, future studies with larger samples will, of course, yield more generalizable findings.

Mean levels of teacher-reported executive problems were low. Although not unexpected with a low-risk sample like the current one, and suggesting that early father-child interactions can predict mild variation in child EF, this reduced variability does imply that the current results may not generalize to higher-risk populations in which more severe executive deficits are likely to be observed (e.g., children with ADHD). Recall also that the BRIEF taps into the presence of executive problems. One may then speculate that this instrument, although often used with nonclinical populations (e.g., Belfort et al., 2016; Clark et al., 2010; Lantrip, Isquith, Koven, Welsh, \& Roth, 2016), may be especially well-suited for clinical populations, which might contribute to explain the non-significant results obtained with the quality of mother-child relationships in this community sample. Furthermore, as discussed above, we assessed mother-child and father-child 
interactions in two different contexts. These different contexts were chosen because they are well suited to each dyad (John et al., 2013; Lamb \& Lewis, 2010; Schoppe-Sullivan et al., 2013). Nonetheless, future studies should investigate the links between the quality of parent-child interactions and child EF manifestations at school using similar interactive contexts for both dyads as well as a counter-balanced order of administration.

This study suggested that toddlers (mostly boys) whose interactions with their fathers are characterized by more harmonious communication, enhanced mutual cooperation, and a more positive emotional ambiance were subsequently considered by their kindergarten teachers to present fewer executive deficits. Accordingly, interventions that target parents' abilities to engage in harmonious, cooperative, and affectively positive interactions with their young children may be one means to promote the development of the executive skills that are considered crucial for children's social and academic adjustment at school entry. In accordance with studies that suggest that parenting interventions with both parents have stronger effects than those with mothers only (e.g., Besnard, Verlaan, Vitaro, Capuano, \& Poulin, 2013; Lundahl, Tollefson, Risser, \& Lovejoy, 2008), the current findings suggest that such intervention efforts should include fathers as well. 


\section{Acknowledgements}

We gratefully acknowledge Chantal Mongeau, Émilie Rochette, Natasha Ballen, Isabelle Demers, Natasha Whipple, Jessica Laranjo, Stéphanie Bordeleau, Véronique Jarry-Boileau, Marie Deschênes, Marie-Ève Bélanger, Andrée-Anne Bouvette-Turcot, Christine Gagné, Célia Matte-Gagné, Gabrielle Lalonde, Marie-Soleil Sirois, Émilie Tétreault, Rachel Perrier, Élizabel Leblanc, Élodie Larose-Grégoire and Nadine Marzougui for help with data collection. Special thanks go to the participating families of the Grandir Ensemble project who generously opened their homes to us. 


\section{References}

Aksan, N., Kochanska, G., \& Ortmann, M. R. (2006). Mutually responsive orientation between parents and their young children: Toward methodological advances in the science of relationships. Developmental Psychology, 42, 833-848. doi:10.1037/0012-1649.42.5.833

Barnett, M. A., \& Scaramella, L. V. (2015). Child fear reactivity and sex as moderators of links between parenting and preschool behavior problems. Development and Psychopathology, 27, 1179-1190. doi:10.1017/s0954579415000759

Belfort, M. B., Rifas-Shiman, S. L., Kleinman, K. P., Bellinger, D. C., Harris, M. H., Taveras, E. M., ... \& Oken, E. (2016). Infant breastfeeding duration and mid-childhood executive function, behavior, and social-emotional Development. Journal of Developmental \& Behavioral Pediatrics, 37, 43-52. doi:10.1097/DBP.0000000000000237

Belsky, J., Booth La Force, C., Bradley, R. H., Brownell, C. A., Burchinal, M., Campbell, S. B., \& Weinraub, M. (2008). Mothers' and fathers' support for child autonomy and early school achievement. Developmental Psychology, 44, 895-907. doi:10.1037/0012-1649.44.4.895

Bernier, A., Beauchamp, M. H., Carlson, S. M., \& Lalonde, G. (2015). A secure base from which to regulate: Attachment security in toddlerhood as a predictor of executive functioning at school entry. Developmental Psychology, 51, 1177-1189. doi:10.1037/dev0000032

Bernier, A., Carlson, S. M., Deschênes, M., \& Matte-Gagné, C. (2012). Social precursors of preschoolers' executive functioning: A closer look at the early caregiving environment. Developmental Science, 15, 12-24. doi:10.1111/j.1467-7687.2011.01093.x

Bernier, A., Carlson, S. M., \& Whipple, N. (2010). From external regulation to self-regulation: Early parenting precursors of young children's executive functioning. Child Development, 81, 326-339. doi:10.1111/j.1467-8624.2009.01397.x 
Besnard, T., Verlaan, P., Vitaro, F., Capuano, F., \& Poulin, F. (2013). Moms and dads count in a prevention program for kindergarten children with behavior problems. Canadian Journal of School Psychology, 28, 219-238. doi:10.1177/0829573513491061

Bierman, K. L., Nix, R. L., Greenberg, M. T., Blair, C., \& Domitrovich, C. E. (2008). Executive functions and school readiness intervention: Impact, moderation, and mediation in the Head Start REDI program. Development and Psychopathology, 20, 821-843. doi:10.1017/S0954579408000394

Blair, C. (2002). School readiness: Integrating cognition and emotion in a neurobiological conceptualization of children's functioning at school entry. American Psychologist, 57, 111-127. doi:10.1037/0003-066X.57.2.111

Blair, C., \& Raver, C. C. (2014). School readiness and self-regulation: A developmental psychobiological approach. Annual Review of Psychology, 66, 12.1-12.21. doi:10.1146/annurev-psych-010814-015221

Boldt, L. J., Kochanska, G., Yoon, J. E., \& Nordling, J. K. (2014). Children's attachment to both parents from toddler age to middle childhood: Links to adaptive and maladaptive outcomes. Attachment \& Human Development, 16, 211-229. doi:10.1080/14616734.2014.889181

Cabrera, N. J., Fitzgerald, H. E., Bradley, R. H., \& Roggman, L. (2014). The ecology of fatherchild relationships: An expanded model. Journal of Family Theory \& Review, 6, 336-354. doi:10.1111/jftr.12054

Cabrera, N. J., Tamis-LeMonda, C. S., Bradley, R. H., Shannon, J. D., \& Hancock, G. R. (2012). Parenting during early childhood in low-income families: Variation by child gender. Family Science, 3, 201-214. doi:10.1080/19424620.2012.783428 
Clark, C. A., Pritchard, V. E., \& Woodward, L. J. (2010). Preschool executive functioning abilities predict early mathematics achievement. Developmental psychology, 46, 11761191. doi:10.1037/a0019672

Cohen, J., \& Cohen, P. (1983). Applied multiple regression/correlation analysis for the behavioral sciences. Hillsdale, NJ: Erlbaum.

Cuevas, K., Deater-Deckard, K., Kim-Spoon, J., Watson, A. J., Morasch, K. C., \& Bell, M. A. (2014). What's mom got to do with it? Contributions of maternal executive function and caregiving to the development of executive function across early childhood. Developmental Science, 17, 224-238. doi:10.1111/desc.12073

Cuevas, K., Hubble, M., \& Bell, M. A. (2012). Early childhood predictors of post-kindergarten executive function: Behavior, parent report, and psychophysiology. Early Education and Development, 23, 59-73. doi:10.1080/10409289.2011.611441

Day, R. D., \& Padilla-Walker, L. M. (2009). Mother and father connectedness and involvement during early adolescence. Journal of Family Psychology, 23, 900-904. doi:10.1037/a0016438

Diamond, A. (2002). Normal development of prefrontal cortex from birth to young adulthood: Cognitive functions, anatomy, and biochemistry. In D. Stuss \& R. Knight (Eds.), Principles of frontal lobe function (pp. 466-503). New York, NY: Oxford University Press.

Diener, M. L., Isabella, R. A., Behunin, M. G., \& Wong, M. S. (2008). Attachment to mothers and fathers during middle childhood: Associations with child gender, grade, and competence. Social Development, 17, 84-101. doi:10.1111/j.1467-9507.2007.00416.x 
Diener, M. L., Mangelsdorf, S. C., McHale, J. L., \& Frosch, C. A. (2002). Infants' behavioral strategies for emotion regulation with fathers and mothers: Associations with emotional expressions and attachment quality. Infancy, 3, 153-174. doi:10.1207/S15327078IN0302_3

Dubois-Comtois, K., Cyr, C., \& Moss, E. (2011). Attachment behavior and mother-child conversations as predictors of attachment representations in middle childhood: A longitudinal study. Attachment \& Human Development, 13, 335-357.

doi:10.1080/14616734.2011.584455

Dubois-Comtois, K., Moss, E., Cyr, C., \& Pascuzzo, K. (2013). Behavior problems in middle childhood: the predictive role of maternal distress, child attachment, and mother-child interactions. Journal of Abnormal Child Psychology, 41, 1311-1324. doi:10.1007/s10802013-9764-6

Fagan, J., Day, R., Lamb, M. E., \& Cabrera, N. J. (2014). Should researchers conceptualize differently the dimensions of parenting for fathers and mothers? Journal of Family Theory \& Review, 6, 390-405. doi:10.1111/jftr.12044

Fay-Stammbach, T., Hawes, D. J., \& Meredith, P. (2014). Parenting influences on executive function in early childhood: A review. Child Development Perspectives, 8, 258-264. doi:10.1111/cdep.12095

Flouri, E., \& Buchanan, A. (2004). Early father's and mother's involvement and child's later educational outcomes. British Journal of Educational Psychology, 74, 141-153. doi:10.1348/000709904773839806

Gioia, G. A., Espy, K. A., \& Isquith, P. K. (2003). Behavior Rating Inventory of Executive Function - Preschool Version (BRIEF-P). Odessa, FL: Psychological Assessment Resources. 
Grossmann, K., Grossmann, K. E., Fremmer-Bombik, E., Kindler, H., Scheuerer-Englisch, H., \& Zimmermann, P. (2002). The uniqueness of the child-father attachment relationship:

Father's sensitive and challenging play as a pivotal variable in a 16-year longitudinal study. Social Development, 11, 307-331. doi:10.1111/1467-9507.00202

Hammond, S. I., Müller, U., Carpendale, J. I. M., Bibok, M. B., \& Liebermann-Finestone, D. P. (2012). The effects of parental scaffolding on preschoolers' executive function. Developmental Psychology, 48, 271-281. doi:10.1037/a0025519

Harris, K. M., Furstenberg, F. F., \& Marmer, J. K. (1998). Paternal involvement with adolescents in intact families: The influence of fathers over the life course. Demography, 35, 201-216. doi: $10.2307 / 3004052$

Hughes, C., \& Ensor, R. (2008). Does executive function matter for preschoolers' problem behaviors? Journal of Abnormal Child Psychology, 36, 1-14. doi:10.1007/s10802-0079107-6

Hughes, C., \& Ensor, R. (2011). Individual differences in growth in executive function across the transition to school predict externalizing and internalizing behaviors and children's selfperceived academic success at age 6. Journal of Experimental Child Psychology, 108, 663676. doi:10.1016/j.jecp.2010.06.005

John, A., Halliburton, A., \& Humphrey, J. (2013). Child-mother and child-father play interaction patterns with preschoolers. Early Child Development and Care, 183, 483-497. doi:10.1080/03004430.2012.711595

Karreman, A., van Tuijl, C., van Aken, M. A., \& Dekovic, M. (2008). Parenting, coparenting, and effortful control in preschoolers. Journal of Family Psychology, 22, 30-40. doi:10.1037/0893-3200.22.1.30 
Kim, S. W., \& Hill, N. E. (2015). Including fathers in the picture: A meta-analysis of parental involvement and students' academic achievement. Journal of Educational Psychology, 107, 917-934. doi:10.1037/edu0000023

Kochanska, G., Aksan, N., Prisco, T. R., \& Adams, E. E. (2008). Mother-child and father-child mutually responsive orientation in the first 2 years and children's outcomes at preschool age: Mechanisms of influence. Child Development, 79, 30-44. doi:10.1111/j.14678624.2007.01109.x

Kochanska, G., \& Kim, S. (2013). Early attachment organization with both parents and future behavior problems: From infancy to middle childhood. Child Development, 84, 283-296. doi:10.1111/j.1467-8624.2012.01852.x

Kochanska, G., \& Murray, K. T. (2000). Mother-child mutually responsive orientation and conscience development: From toddler to early school age. Child Development, 71, 417431. doi:10.1111/1467-8624.00154

Kraybill, J. H., \& Bell, M. A. (2013). Infancy predictors of preschool and post-kindergarten executive function. Developmental Psychobiology, 55, 530-538. doi:10.1002/dev.21057

Ladd, G. W. \& Price, J. M. (1987). Predicting children's social and school adjustment following the transition from preschool to kindergarten. Child Development, 58, 1168-1189. doi:10.1111/j.1467-8624.1987.tb01450.x

Lamb, M. E., \& Lewis, C. (2010). The development and significance of father-child relationships in two-parent families. In M. E. Lamb (Ed.), The role of the father in child development (5th ed., pp. 94-153). Hoboken, NJ: Wiley. 
Lantrip, C., Isquith, P. K., Koven, N. S., Welsh, K., \& Roth, R. M. (2016). Executive function and emotion regulation strategy use in adolescents. Applied Neuropsychology: Child, 5, 5055. doi:10.1080/21622965.2014.960567

Leaper, C. (2002). Parenting girls and boys. In M. H. Bornstein, Handbook of parenting: Children and parenting (2nd ed., vol. 1, pp. 189-225). Mahwah, NJ: Erlbaum.

Leidy, S. M., Schofield, J. T., \& Parke, D. R. (2013). Fathers' contributions to children's social development. In N. J. Cabrera \& C.S. Tamis-LeMonda (Eds.), Handbook of father involvement: Multidisciplinary perspectives (pp. 151-167). New York, NY: Routledge.

Lindsey, E. W., \& Mize, J. (2001). Contextual differences in parent-child play: Implications for children's gender role development. Sex Roles, 44, 155-176. doi:10.1023/A:1010950919451

Lundahl, B. W., Tollefson, D., Risser, H., \& Lovejoy, M. C. (2008). A meta-analysis of father involvement in parent training. Research on Social Work Practice, 18, 97-106. doi: $10.1177 / 1049731507309828$

Manlove, E. E. \& Vernon-Feagans, L. (2002). Caring for infant daughters and sons in dual-earner households: Maternal reports of father involvement in weekday time and tasks. Infant and Child Development, 11, 305-320. doi:10.1002/icd.260

Martin, A., Ryan, R. M., \& Brooks-Gunn, J. (2007). The joint influence of mother and father parenting on child cognitive outcomes at age 5. Early Childhood Research Quarterly, 22, 423-439. doi:10.1016/j.ecresq.2007.07.001

McDowell, D. J., \& Parke, R. D. (2009). Parental correlates of children's peer relations: An empirical test of a tripartite model. Developmental Psychology, 45, 224-235. doi:10.1037/a0014305 
Meuwissen, A. S., \& Carlson, S. M. (2015). Fathers matter: The role of father parenting in preschoolers' executive function development. Journal of Experimental Child Psychology, 140, 1-15. doi:10.1016/j.jecp.2015.06.010

Moss, E., Cyr, C., \& Dubois-Comtois, K. (2004). Attachment at early school age and developmental risks: Examining family contexts and behaviour problems of controllingcaregiving, controlling-punitive, and behaviourally disorganized children. Developmental Psychology, 40, 519-532. doi:10.1037/0012-1649.40.4.519

National Institute of Child Health and Human Development (NICHD) Early Child Care Research Network. (2000). Factors associated with fathers' caregiving activities and sensitivity with young children. Journal of Family Psychology, 14, 200-219. doi:10.1037/08933200.14.2.200

Nettle, D. (2008). Why do some dads get more involved than others? Evidence from a large British cohort. Evolution and Human Behavior, 29, 416-423. doi:10.1016/j.evolhumbehav.2008.06.002

Newland, L. A., Chen, H., Coyl-Shepherd, D. D., Liang, Y., Carr, E. R., Dykstra, E., \& Gapp, S. C. (2013). Parent and child perspectives on mothering and fathering: The influence of ecocultural niches. Early Child Development and Care, 183, 534-552. doi:10.1080/03004430.2012.711598

Owen, M. T., Caughy, M. O., Hurst, J. R., Amos, M., Hasanizadeh, N., \& Mata-Otero, A. (2013). Unique contributions of fathering to emerging self-regulation in low-income ethnic minority preschoolers. Early Child Development and Care, 183, 464-482. doi:10.1080/03004430.2012.711594 
Paquette, D. (2004). Theorizing the father-child relationship: Mechanisms and developmental outcomes. Human Development, 47, 193-219. doi:10.1159/000078723

Pianta, R. C., Cox, M. J., \& Snow, K. L. (2007). School readiness and the transition to kindergarten in the era of accountability. Baltimore, MD: Paul H Brookes Publishing.

Roskam, I., Stievenart, M., Meunier, J. C., \& Noël, M. P. (2014). The development of children's inhibition: Does parenting matter? Journal of Experimental Child Psychology, 122, 166182. doi:10.1016/j.jecp.2014.01.003

Ruiz-Ortiz, R., Braza, P., Carreras, R., \& Muñoz, J. M. (2017). Differential effects of mother's and father's parenting on prosocial and antisocial behavior: Child sex moderating. Journal of Child and Family Studies. Advance online publication. doi:10.1007/s10826-017-0726-4

Saracho, O. N. (2007). Fathers and young children's literacy experiences in a family environment. Early Child Development and Care, 177, 403-415.

doi:10.1080/03004430600563034

Schoppe-Sullivan, S. J., Diener, M. L., Mangelsdorf, S. C., Brown, G. L., McHale, J. L., \& Frosch, C. A. (2006). Attachment and sensitivity in family context: The roles of parent and infant gender. Infant and Child Development, 15, 367-385. doi:10.1002/icd.449

Schoppe-Sullivan, S. J., Kotila, L. E., Jia, R., Lang, S. N., \& Bower, D. J. (2013). Comparisons of levels and predictors of mothers' and fathers' engagement with their preschool-aged children. Early Child Development and Care, 183, 498-514. doi:10.1080/03004430.2012.711596

Shonkoff, J. P., Duncan, G. G., Fisher, P. A., Magnuson, K., Raver, C. C., \& Yoshikawa, H. (2011). Building the Brain's “Air Traffic Control” System: How Early Experiences Shape the Development of Executive Function: (Working Paper No. 11). Retrieved from Center of 
the Developing Child website: http://developingchild.harvard.edu/wpcontent/uploads/2011/05/How-Early-Experiences-Shape-the-Development-of-ExecutiveFunction.pdf

Statistics Canada (2006). Visible minority population, by census metropolitan areas. Québec, Sherbrooke, Trois-Rivières, Montréal, Ottawa-Gatineau (2006 Census of Population). Retrieved from the Statistics Canada website: http://www.statcan.gc.ca/tablestableaux/sum-som/101/cst01/demo53b-eng.htm

Statistics Canada (2011). Population by home language, by province and territory. Quebec, Ontario, Manitoba, Saskatchewan (2011 Census of Population). Retrieved from the Statistics Canada website: http://www.statcan.gc.ca/tables-tableaux/sumsom/101/cst01/demo61b-eng.htm

Steele, H., \& Steele, M. (2005). Understanding and resolving emotional conflict: The London parent-child project. In K. E. Grossmann, K. Grossmann \& E. Waters (Eds.), Attachment from infancy to adulthood: The major longitudinal studies (pp. 197-164). New York, NY: Guilford Press.

StGeorge, J., Fletcher, R., Freeman, E., Paquette, D., \& Dumont, C. (2015). Father-child interactions and children's risk of injury. Early Child Development and Care, 185, 14091421. doi:10.1080/03004430.2014.1000888

Tamis-LeMonda, C.S., Baumwell, L., \& Cabrera, N.J. (2013). Fathers' role in children's language development. In N. J. Cabrera \& C.S. Tamis-LeMonda (Eds.), Handbook of father involvement: Multidisciplinary perspectives (pp. 151-167). New York, NY: Routledge. 
Tamis-LeMonda, C. S., Shannon, J. D., Cabrera, N. J., \& Lamb, M. E. (2004). Fathers and mothers at play with their 2-and 3-year-olds: Contributions to language and cognitive development. Child Development, 75, 1806-1820. doi:10.1111/j.1467-8624.2004.00818.x

Towe-Goodman, N. R., Willoughby, M., Blair, C., Gustafsson, H. C., Mills-Koonce, W. R., \& Cox, M. J. (2014). Fathers' sensitive parenting and the development of early executive functioning. Journal of Family Psychology, 28, 867-876. doi:10.1037/a003812

Tung, I., Li, J. J., \& Lee, S. S. (2012). Child sex moderates the association between negative parenting and childhood conduct problems. Aggressive Behavior, 38, 239-251. doi:10.1002/ab.21423

Varghese, C., \& Wachen, J. (2016). The determinants of father involvement and connections to children's literacy and language outcomes: Review of the literature. Marriage \& Family Review, 52, 331-359. doi:0.1080/01494929.2015.1099587

Verschueren, K., \& Marcoen, A. (1999). Representation of self and socioemotional competence in kindergartners: Differential and combined effects of attachment to mother and to father. Child Development, 70, 183-201. doi:10.1111/1467-8624.00014

Zelazo, P. D., Carlson, S. M., \& Kesek, A. (2008). The development of executive function in childhood. In C. Nelson \& M. Luciana (Eds.), Handbook of developmental cognitive neuroscience (pp. 553-574). Cambridge, MA: MIT Press. 
Table 1

Descriptive Statistics for all Main Study Variables

\begin{tabular}{lcccc}
\hline Variable & Minimum & Maximum & Mean & $\begin{array}{c}\text { Standard } \\
\text { Deviation }\end{array}$ \\
\hline Mother-child interactions & 1.17 & 4.92 & 3.13 & 0.87 \\
Father-child interactions & 1 & 4.92 & 3.03 & 0.95 \\
Inhibition & 26 & 56 & 32.41 & 7.67 \\
Flexibility & 19 & 38 & 23.20 & 4.04 \\
Metacognition & 26 & 47 & 30.85 & 4.93 \\
Global executive composite & 63 & 102 & 74.74 & 11.17 \\
& & & & \\
\hline
\end{tabular}


Table 2

Zero-Order Correlations Among all Main Variables and Relevant Covariates

\begin{tabular}{|c|c|c|c|c|c|c|c|c|c|c|}
\hline & 1 & 2 & 3 & 4 & 5 & 6 & 7 & 8 & 9 & 10 \\
\hline 1. Mother-child interactions & $\ldots$ & $.50^{* * *}$ & -.01 & -.00 & -.18 & -.11 & $.19^{t}$ & $-.19^{\mathrm{t}}$ & $.22^{*}$ & .10 \\
\hline 2. Father-child interactions & & $\ldots$ & -.23 & -.17 & $-.26^{\mathrm{t}}$ & $-.29^{*}$ & .12 & .05 & $.20^{\mathrm{t}}$ & $.25^{*}$ \\
\hline 3. Inhibition & & & $\ldots$ & $.84^{* * *}$ & $.68^{* * *}$ & $.93^{* * *}$ & .03 & .01 & -.03 & .02 \\
\hline 4. Flexibility & & & & $\ldots$ & $.60^{* * * *}$ & $.85^{* * *}$ & .18 & -.12 & .01 & -.01 \\
\hline 5. Metacognition & & & & & $\ldots$ & $.89^{* * *}$ & -.24 & -.09 & -.06 & -.22 \\
\hline 6. Global executive composite & & & & & & $\ldots$ & -.08 & -.08 & -.03 & -.08 \\
\hline 7. Child sex & & & & & & & $\ldots$ & .14 & .16 & -.11 \\
\hline 8. Older siblings & & & & & & & & $\ldots$ & -.03 & -.02 \\
\hline 9. Child age (T1) & & & & & & & & & $\ldots$ & .12 \\
\hline 10. Family SES & & & & & & & & & & $\ldots$ \\
\hline
\end{tabular}

Child sex is coded: $0=$ boy; $1=$ girl.

Older siblings is coded: $0=$ no older siblings; $1=$ one or more.

$\mathrm{SES}=$ Socioeconomic status

${ }^{\mathrm{t}} p<.10 . * p<.05 . * * * p<.001$. 
Table 3

Summary of Regression Analyses Predicting the Three Executive Function Indices and the Global Executive Composite

\begin{tabular}{lcccc}
\hline Blocks and predictors & Inhibition & Flexibility & Metacognition & $\begin{array}{c}\text { Global executive } \\
\text { composite }\end{array}$ \\
\hline & $\beta$ & $\beta$ & $\beta$ & $\beta$ \\
\hline 1. Child sex & .11 & .26 & -.17 & .02 \\
Older siblings & .04 & -.12 & -.05 & -.05 \\
Child age (T1) & .03 & .03 & .02 & .04 \\
Family SES & .01 & .01 & -.25 & -.10 \\
2. Mother-child relationship (A) & .13 & .00 & .04 & .08 \\
Father-child relationship (B) & $-.36^{\mathrm{t}}$ & -.24 & -.28 & $-.38^{*}$ \\
3. Interactive term (AxB) & -.05 & -.10 & -.08 & -.10 \\
\cline { 2 - 5 } Total explained variance & $9.1 \%$ & $10 \%$ & $17.2 \%$ & $12.6 \%$ \\
\hline
\end{tabular}

Note. The coefficients shown are those in the final model, while accounting for all other predictors.

Child sex is coded: $0=$ boy; $1=$ girl.

Older siblings is coded: $0=$ no older siblings; $1=$ one or more.

SES = Socioeconomic status

${ }^{t} p<.10 . * p<.05$. 